\title{
Risk Factors of Zinc Deficiency in Children with Atopic Dermatitis
}

\author{
${ }^{1}$ Weill Cornell Medical College, Ar-Rayyan, Qatar \\ ${ }^{2}$ Section of Pediatric Allergy-Immunology, Department of Pediatrics, Hamad Medical Corporation, Doha, Qatar \\ ${ }^{3}$ Departments of Biostatistics and Medical Informatics, Cerrahpaşa Faculty of Medicine, Istanbul University, Istanbul, \\ Turkey \\ ${ }^{4}$ Departments of Public Health, Medipol International School of Medicine, Istanbul Medipol University, Istanbul, Turkey
}

\section{KEY WORDS}

zinc deficiency; risk factor; severe; atopic

dermatitis; $\operatorname{Ig} E$

\author{
Corresponding author \\ Mohammad S. Ehlayel \\ Section of Allergy-Immunology \\ Department of Pediatrics, \\ Hamad Medical Corporation \\ PO Box 3050, Doha, State of Qatar \\ Phone: +974 4439 2834-22840 \\ Fax: +97444439571 \\ E-mail: mehlayel@hamad.qa
}

Doi

10.23822/EurAnnACI.1764-1489.114

\begin{abstract}
Summary
Background and objectives. Zinc deficiency increases risk of infections, allergies and autoimmunity. We wished to determine risk factors in severe atopic dermatitis $(A D)$ and identify of hypozincemia rate. Materials and methods. Retrospective study done on $A D$ children ( $\leq 14$ years) with serum zinc test. Data included demographic and laboratory tests (serum zinc level, IgE, food-specific IgE), and skin tests. Results. 168 AD children, aged 38.9 months with concomitant allergies in 47 (28\%), family history of allergies in 131 (80\%), and parental consanguinity in 134 (79.9\%). AD was mild in 12 (7.2\%, SCORAD 15.8) children, moderate in 41 (24.5\%, SCORAD 30.4), and severe in 115 (68.3\%, SCORAD 69.4). Hypozincemia was observed in $42(25 \%$, zinc $8.6 \pm 1.1 \mu \mathrm{moI} / \mathrm{L})$ children and associated only with severe $A D(p=$ $0.0418)$ and elevated $\operatorname{IgE}(p=0.001)$. Conclusions. Hypozincemia is rather prevalent in $A D$, and severe $A D$ and high IgE increase its risk. An adjunct oral zinc may help reducing severe poorly responsive $A D$.
\end{abstract}

\section{Introduction}

Zinc is a crucial trace element for biological processes of the cells. Zinc plays an important key role in a large number of enzymes and is involved in cell activities including cell-cell interactions, proliferation, and differentiation. It exerts a regulatory role on the immune system, with evidence indicating that zinc deficiency propagates inflammation in autoimmune and allergic diseases (1). A recent, large systematic review and meta-analysis on zinc status and autoimmunity indicated that zinc levels were consistently lower in autoimmune patients than controls (2). This study included various types of autoimmune diseases, such as alopecia areata, Hashimoto's thyroiditis, juvenile idiopathic arthritis, multiple sclerosis, pemphigus vulgaris, rheumatoid arthritis, systemic lupus erythematosus, Sjogren's syndrome, and type 1 diabetes (2). Whereas mild $\mathrm{AD}$ represents more than $70-80 \%$ of patients, moderate-to-severe AD comprises $20 \%$ of cases (3). Severe AD is associated with uncommon but significant complications such as infections (4), poor weight gain, marked malnutrition, or trace elements deficiency (5). Published literature on zinc deficiency and its association with $\mathrm{AD}$ is increasing. The significance of hypozincemia in $\mathrm{AD}$ seems to be poorly understood. There are no studies on how common zinc deficiency is in moderate-to-severe $\mathrm{AD}$ among children and on the risk factors. The aims of this study were to determine how common zinc deficiency is among children with $\mathrm{AD}$, and to determine any risk factors for zinc deficiency in these children.

\section{Materials and methods}

In this retrospective study, we reviewed records of all children, 14 years or less, seen at our Pediatric Allergy-Immunology Clinics at Hamad General Hospital with severe $\mathrm{AD}$ and serum zinc level tested. Serum zinc level was considered low in AD chil- 
dren if less than $9.8 \mathrm{umol} / \mathrm{L}(64 \mathrm{ug} / \mathrm{L})(6)$. We excluded children with chronic GI disorders (e.g. malabsorptive syndromes, pancreatic disease, cirrhosis, and blind-loop syndrome), dietary problems or restrictions (e.g. total parenteral nutrition, severely restrictive diets, anorexia, and bulimia), trauma (e.g. burns, post-surgery), malignancy, blood transfusions in the preceding 3 months, renal disorders (e.g. tubular disease, nephrotic syndrome, dialysis), severe chronic infections, certain medications (e.g. anti-metabolites, chelators), diabetes mellitus, hemolytic anemia, collagen vascular disease, acrodermatitis enteropathica, or being on zinc supplements.

Each patient's record was reviewed and data, collected on a standard form, included patient's age, sex, clinical presentation, the presence of other allergies, and family history of allergic diseases. SCORing Atopic Dermatitis (SCORAD) was collected. Each patient's weight and height were collected, from which we calculated body mass index (BMI). We also collected results of CBC, white blood cell count (WBC) with differential counts, total serum IgE. Status of food allergy, whenever available, was reviewed and recorded as per food allergens tests such as skin prick tests or specific-IgE to a panel of 8 common food allergens, including cow's milk, egg, wheat, tree nuts, peanut, soy, fish, and seafood. The study was conducted in accordance with the Declaration of Helsinki, and the protocol was approved by the Institutional Review Board (IRB) at Hamad Medical Corporation (RMC No. 14193/14).

\section{Results}

A total of 168 children with moderate-to-severe AD had zinc level measured. There were 89 (53\%) males and 79 (47\%) females, with a males-to-female ratio of 1.1:1. Mean age $( \pm$ SD) was $38.9 \pm 38.6$ months. Simultaneous other allergic diseases were observed in 47 children (28\%), mainly asthma and urticaria. Family history of allergic diseases was positive in $131(80 \%)$ children, with $66(39.2 \%)$ positive for $\mathrm{AD}, 35$ (21\%) for asthma, and the rest positive for various combinations of asthma, $\mathrm{AD}$, allergic rhinitis, urticaria, and anaphylaxis. Parental consanguinity was noticed in 134 (79.9\%) children. Regarding AD severity, 12 (7.2\%) children had mild AD with SCORAD $15.8 \pm 3.2$ (95\% CI 13.3-18.8), $41(24.5 \%)$ moderate, SCORAD $30.4 \pm 6.7$ (95\% CI 28.2 $32.5)$, and $115(68.3 \%)$ severe with SCORAD $69.4 \pm 17.0$, (95\% CI 62-77).

Serum zinc was low in 42 patients (25\%), with level of $8.6 \pm$ $1.1 \mu \mathrm{moI} / \mathrm{L}$ (95\% CI 8.1-9.0). Table I shows that there is no significant difference between the low-zinc group compared to the normal-zinc group in term of age, sex, the presence of other allergies or family history of allergic diseases.

AD severity scores, WBC, peripheral eosinophil counts, total $\mathrm{IgE}$ levels, number of positive food allergens, and serum zinc levels for both groups are shown in table II.

Table I - Demographic and clinical characteristics of AD children.

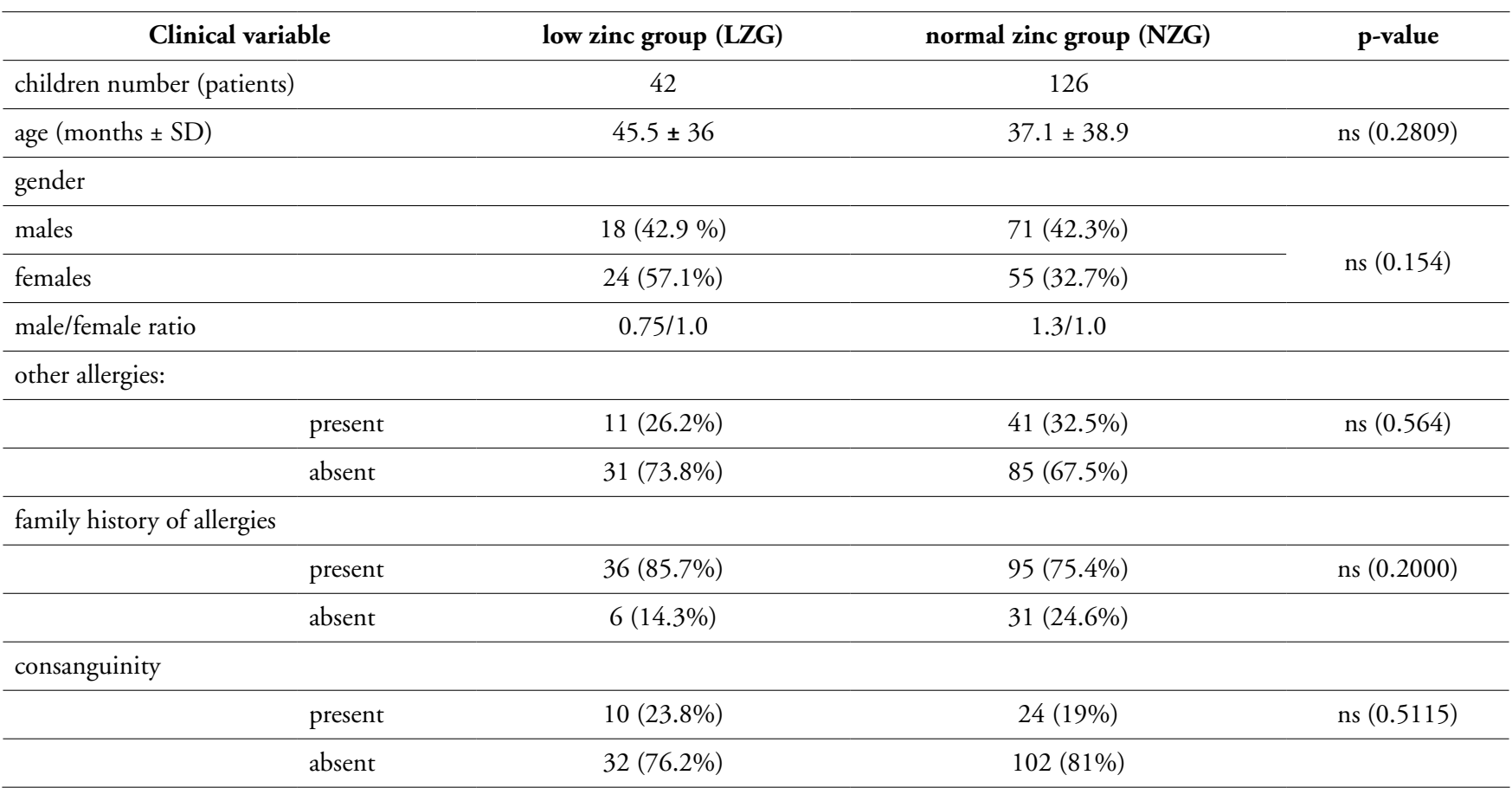


There is a significant difference between the proportion of children with severe $\mathrm{AD}$ in the low-zinc group compared to the normal-zinc group, as depicted in figure $\mathbf{1}$.

\section{Discussion}

The present study demonstrates that zinc deficiency is present in $25 \%$ of children with severe AD. They were older than children with normal serum zinc levels, and family history of allergic diseases. We observed that severe $\mathrm{AD}$ and high serum IgE are associated with zinc deficiency. The proportion of patients with severe (SCORAD index > 40) AD was significantly higher in the low-zinc group compared to normal-zinc group. We did not find an association between low zinc in $\mathrm{AD}$ and co-existence of other allergic diseases, parental consanguinity, number of food allergens, WBC, and or peripheral blood eosinophilia.

The role of zinc as a micronutrient in $\mathrm{AD}$ has been investigated in a limited number of studies, with contradictory results, some investigators reported lower levels (5-7) whereas others found no differences (8-10). However, a recent systematic and meta-analysis on and atopic dermatitis conclude that low zinc is associated with $\mathrm{AD}$ (11). In 1984, a case-controlled study on 144 children (65 AD, 79 controls) showed that the mean serum zinc of the $\mathrm{AD}$ patients was significantly lower $(\mathrm{p}<0.0001)$ than

Figure 1 - Distribution of patients according to AD severity in low-zinc (LZG) compared to normal zinc group (NZG).

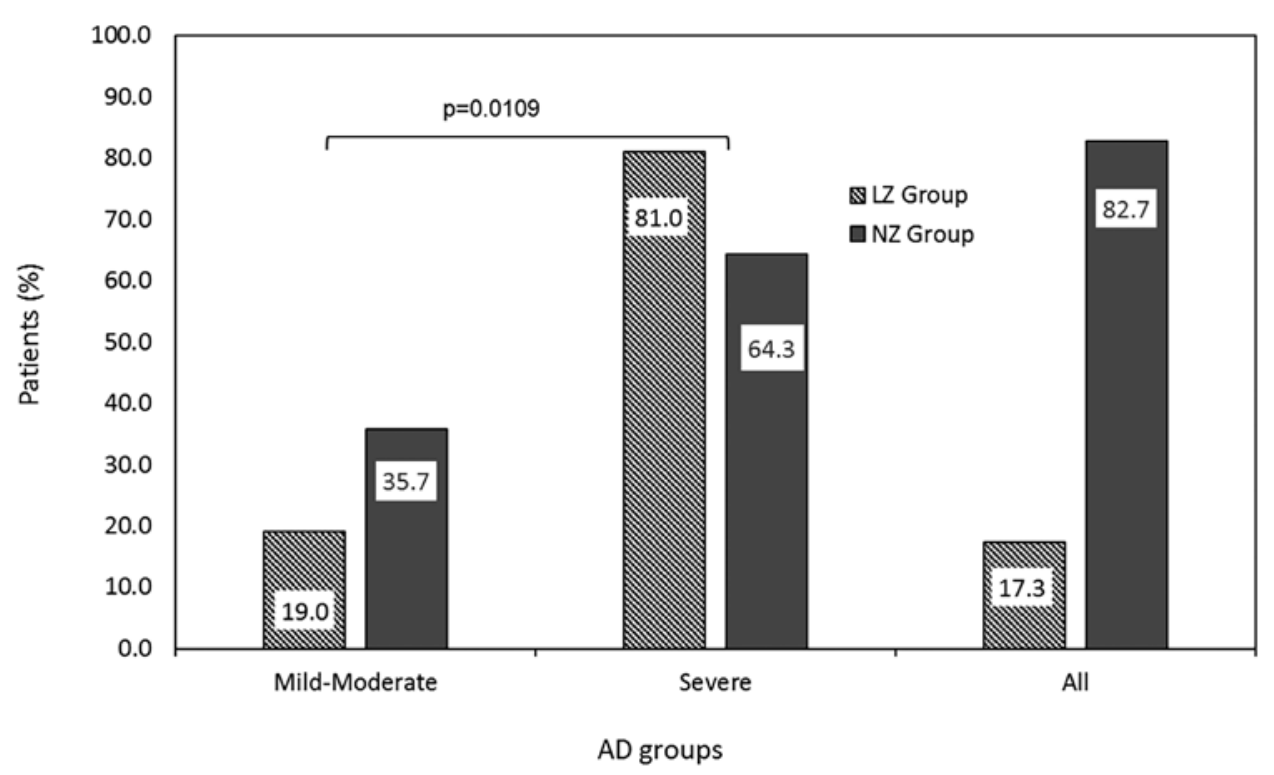

Table II - Disease severity index and laboratory variables of children with severe AD.

\begin{tabular}{|c|c|c|c|}
\hline laboratory variable & low zinc group & normal zinc group & p-value \\
\hline total SCORAD (number) & $63.9 \pm 23.3$ & $53.9 \pm 25.0$ & 0.0418 \\
\hline no. of positive food allergens & $2.1 \pm 1.6$ & $1.9 \pm 1.7$ & ns $(0.7492)$ \\
\hline $\operatorname{AEC~(cells/ul)~}{ }^{1}$ & $963.2 \pm 860.8$ & $981.9 \pm 964.9$ & ns $(0.8256)$ \\
\hline serum IgE (KU/l) & $6,818.7 \pm 8,357.2$ & $2,161.7 \pm 4,841.1$ & 0.001 \\
\hline serum zinc $(\mu \mathrm{mol} / \mathrm{L})$ & $8.6 \pm 1.1$ & $12.4 \pm 1.9$ & $<0.001$ \\
\hline
\end{tabular}

${ }^{1} \mathrm{AEC}$, absolute eosinophil count. 
that of the controls (12). Endre et al. study on 134 children who were admitted to hospital with $\mathrm{AD}$, found 41 (29.1\%) with low serum zinc levels (13). El-Kholy et al. demonstrated that in 18 $\mathrm{AD}$ children and 20 controls, serum and hair zinc levels were significantly lower $(\mathrm{p}<0.0001)$ in $\mathrm{AD}$ children in comparison to the control subjects (14). In contrast in 1990, David et al. study on 134 children with atopic eczema and 112 controls failed to prove the hypothesis that atopic eczema is associated with a non-specific decrease in the serum concentration of trace metals, including zinc (8). This study supports previous findings of Endre et al. that serum zinc was low in $29.1 \%$ of 134 children who were admitted to hospital with $\mathrm{AD}(8)$.

Our results revealed that $\mathrm{AD}$ severity is associated with low zinc in $\mathrm{AD}$. These findings are compatible with previous studies $(11,15)$. Karabacak et al. demonstrated in a recent, controlled study on $\mathrm{AD}$ patients ( $\mathrm{n}=67$ study patients and 49 controls; mean age 17.9 years) that serum erythrocyte zinc level, but not the serum level, had a significant negative correlation with SCORAD index (15). Although some people take erythrocyte zinc level as the most sensitive clinical marker of zinc level in AD (8), in our study we found that serum zinc was low.

This is the first study to assess the association between serum IgE levels and zinc levels in children with $\mathrm{AD}$. Our study shows that study subjects with increased total serum IgE levels had significantly lower zinc levels. Recent data on the participants in the $5^{\text {th }}$ Korean National Health and Nutrition Examination Survey $2010(\mathrm{n}=8,958)$, and on 1,867 adults, confirmed an association between serum zinc status and allergic sensitization in adults (16). There was a negative correlation between serum zinc levels and total $\operatorname{IgE}$ and allergen-specific IgE levels. A controlled study on children with food allergy (IgE- and non-IgE mediated), revealed that they had low serum levels of zinc (a cofactor of superoxide dismutase ) and selenium (a cofactor of glutathione peroxidase), and low concentrations of superoxide dismutase and glutathione peroxidase (17). These enzymes increased after elimination diet. Agin's study on a total of 48 subjects with allergic (skin prick tested) asthma, of mean age $32.8 \pm$ 9.9 years (range 15-48 years), showed that hypozincemic group $(23 \%)$ had a markedly higher mean of total IgE level than normozincemic controls (18). Using HR-1 hairless mice, mice fed a diet with low magnesium and zinc developed AD-like (skin dryness, wrinkle-like changes, scratching, reduced skin water content, high transepidermal water loss), and a significantly ( $\mathrm{p}$ $<0.001$ ) elevated serum IgE compared with control mice fed standard diet (19). Although the exact role of zinc in $\mathrm{AD}$ immunopathology is not well determined, it seems to work through immune regulation. Zinc deficiency was associated with immune dysregulation. Regulatory $\mathrm{T}$ (Treg) cells play a key role in immune suppression, promoting tolerance to allergens, and preventing allergic responses including the chronic skin inflammation in $\mathrm{AD}$.
They regulate allergen-specific Th2 immune responses and B cell IgE production, block of naïve CD4+ Tconv cells conversion into allergen-specific Th2 T cells, control B cells, and block their $\mathrm{IgE}$ production (20).

The percentage of Tregs in allergic patients (2.3\%) was significantly lower in $\mathrm{AD}$ patients in comparison to healthy controls $(4.6 \%, \mathrm{p}=0.003)$, even in the asymptomatic $\mathrm{AD}$ or food allergy subjects (21). Atopic food-allergic children also had decreased percentages of Treg cells compared with healthy age-matched healthy controls (22). In a recent mouse model study, allergen-specific immunotherapy revealed local suppression of Th2 and infiltration of Treg cells into the skin, and induced local and systemic Treg cells and regulatory NK cells (23). In addition to the results that Treg cells percentage and TGF- $\beta$ level were decreased in $\mathrm{AD}$ lesions, Treg cells percentage negatively correlated with $\mathrm{AD}$ severity score (24).

Conversely, zinc supplementation was demonstrated to restore immune regulatory mechanism. In vitro, zinc supplementation significantly diminished the differentiation of Th9 cells, key players promoting immune-mediated diseases, including allergic inflammation (25), and was capable, by modulating molecular targets Foxp3, KLF-10, and IRF-1, to ameliorate the immune reaction by enhancement of antigen-specific iTreg cells (26). Zinc was also able to induce dendritic cell tolerogenic phenotype and enhanced regulatory $\mathrm{T}$ cell-Th17 balance (27). A study on peripheral blood mononuclear cells (PBMCs) from non-atopic and atopic subjects treated with timothy grass allergen pre-incubated with or without zinc, revealed that zinc enhanced regulatory $\mathrm{T}$ cell numbers and suppressed their proliferation through a significant shift from IL-10 to the Th1 cytokine IFN- $\gamma(28)$.

The strength of this study is that it includes a large sample of $\mathrm{AD}$ children, and that all were evaluated by the same physician (ME) thus eliminating any inter-rater difference during $\mathrm{AD}$ SCORAD assessment. It may appear that zinc testing in $\mathrm{AD}$ children is a possible bias. In fact, it is not. We were prompted to study zinc level as part of workup of poor weight and linear growth in these severe AD children (29). The main limitations of this study include its retrospective design. The rate of zinc deficiency might be overrepresented among AD children as these cases are referred to a tertiary care center, but the study concentrates on those with severe form of $\mathrm{AD}$. It may appear that serum zinc level is a limitation; however, there are numerous studies that used serum samples, not hair samples, as a valid test for determining zinc levels in allergic diseases, including $\mathrm{AD}$.

\section{Conclusions}

Zinc deficiency is quite common among AD children. Severe $\mathrm{AD}$ and high total IgE are risk factors associated with zinc deficiency. In severe $\mathrm{AD}$ poorly responsive standard therapy, an ad- 
junct oral zinc supplementation might be warranted to reduce disease severity.

\section{Acknowledgements}

This study was supported in part by Research Medical Center of Hamad Medical Corporation (RMC No. 14193/14).

\section{Conflict of interest}

The authors declare they have no conflict of interest.

\section{References}

1. Maywald M, Wessels I, Rink L. Zinc Signals and Immunity. Int J Mol Sci 2017. doi:10.3390/ijms18102222.

2. Sanna A, Firinu D, Zavattari P, Valera P. Zinc status and autoimmunity: a systematic review and meta-analysis. Nutrients 2018; 10(1):68.

3. Arkwright PD, Motala C, Subramanian H et al. Management of difficult-to-treat atopic dermatitis. J Allergy Clin Immunol Pract 2013; 1(2):142-151.

4. Kim KH. Clinical pearls from atopic dermatitis and its infectious complications. Br J Dermatol 2014; 170(Suppl 1):25-30.

5. Toyran M, Kaymak M, Vezir E et al. Trace element levels in children with atopic dermatitis. J Investig Allergol Clin Immunol 2012; 22(5):341-344.

6. Lin $\mathrm{CN}$, Wilson $\mathrm{A}$, Church $\mathrm{BB}$ et al. Pediatric reference intervals for serum copper and zinc. Clin Chim Acta 2012; 413(5-6):612615.

7. Kim JE, Yoo SR, Jeong MG et al. Hair zinc levels and the efficacy of oral zinc supplementation in patients with atopic dermatitis. Acta Derm Venereol 2014; 94(5):558-562.

8. David TJ, Wells FE, Sharpe TC et al. Serum levels of trace metals in children with atopic eczema. Br J Dermatol 1990; 122(4):485489.

9. Bruske K, Salfeld K. (Zinc and its status in some dermatologic diseases--a statistical assessment). Z Hautkr 1987; 62Suppl1:125-131.

10. Hinks LJ, Young S, Clayton B. Trace element status in eczema and psoriasis. Clin Exp Dermatol 1987; 12(2):93-97.

11. Gray NA, Dhana A, Stein DJ, Khumalo NP. Zinc and atopic dermatitis: a systematic review and meta-analysis. J Eur Acad Dermatol Venereol 2019; 33(6):1042-1050.

12. David TJ, Wells FE, Sharpe TC, Gibbs AC. Low serum zinc in children with atopic eczema. Br J Dermatol 1984; 111(5):597601.

13. Endre L, Gergely A, Osvath P et al. (Incidence of food allergy and zinc deficiency in children treated for atopic dermatitis). Orvosi hetilap 1989; 130(46):2465-2469.
14. el-Kholy MS, Gas Allah MA, el-Shimi S et al. Zinc and copper status in children with bronchial asthma and atopic dermatitis. J Egypt Public Health Assoc 1990; 65(5-6):657-668.

15. Karabacak E, Aydin E, Kutlu A et al. Erythrocyte zinc level in patients with atopic dermatitis and its relation to SCORAD index. Adv Dermatol Allergol /Postępy Dermatologii i Alergologii 2016; 33(5):349-352.

16. Seo H-M, Kim YH, Lee JH et al. Serum Zinc Status and Its Association with Allergic Sensitization: The Fifth Korea National Health and Nutrition Examination Survey. Sci Rep 2017; 7:12637.

17. Kamer B, Wąsowicz W, Pyziak K et al. Role of selenium and zinc in the pathogenesis of food allergy in infants and young children. Arch Med Sci 2012; 8(6):1083-1088.

18. Agin Kh. A survey on zinc status among chronic allergic asthma. Int J Forensic Med Toxicol Sci 2015; 5(1):1-7.

19. Makiura M, Akamatsu H, Akita $\mathrm{H}$ et al. Atopic dermatitis-like symptoms in HR-1 hairless mice fed a diet low in magnesium and zinc. J Int Med Res 2004; 32(4):392-399.

20. Noval Rivas M, Chatila TA. Regulatory T cells in allergic diseases. J Allergy Clin Immunol 2016; 138(3):639-652.

21. Stelmaszczyk-Emmel A, Zawadzka-Krajewska A, Szypowska A et al. Frequency and activation of CD4+CD25 FoxP3+ regulatory $\mathrm{T}$ cells in peripheral blood from children with atopic allergy. Int Arch Allergy Immunol 2013; 162(1):16-24.

22. Prince BT, Devonshire AL, Erickson KA et al. Regulatory T-cell populations in children are affected by age and food allergy diagnosis. J. Allergy Clin. Immunol. 2017; 140(4):1194-1196.e16.

23. Shin JU, Kim SH, Noh JY et al. Allergen-specific immunotherapy induces regulatory $\mathrm{T}$ cells in an atopic dermatitis mouse model. Allergy 2018; 73(9):1801-1811.

24. Ma L, Xue H-B, Guan X-H et al. The Imbalance of Th17 cells and CD4(+) CD25(high) Foxp3(+) Treg cells in patients with atopic dermatitis. J Eur Acad Dermatol Venereol 2014; 28(8):1079-1086.

25. Maywald M, Wang F, Rink L. Zinc supplementation plays a crucial role in $\mathrm{T}$ helper 9 differentiation in allogeneic immune reactions and non-activated T cells. J Trace Elem Med Biol 2018; 50:482488.

26. Maywald M, Rink L. Zinc supplementation induces CD4(+) CD25(+)Foxp3(+) antigen-specific regulatory $\mathrm{T}$ cells and suppresses IFN-gamma production by upregulation of Foxp3 and KLF-10 and downregulation of IRF-1. Eur J Nutr 2017; 56(5):1859-1869.

27. George MM, Subramanian Vignesh K, Landero Figueroa JA et al. Zinc induces dendritic cell tolerogenic phenotype and skews regulatory T Cell-Th17 balance. J Immunol 2016; 197(5):1864-1876.

28. Rosenkranz E, Hilgers RD, Uciechowski P et al. Zinc enhances the number of regulatory $\mathrm{T}$ cells in allergen-stimulated cells from atopic subjects. Eur J Nutr 2017; 56(2):557-567.

29. Ehlayel M, Ashraf S, De Sanctis V. Linear growth and nutritional parameters in adolescents with severe atopic dermatitis. Rivista Italiana di Medicina dell'Adolescenza 2016; 14(1):19-22. 